\title{
Skinfold thickness, body mass index and ischaemic heart disease
}

\author{
J D IMESON, ANDREW P HAINES, AND T W MEADE \\ From the MRC Epidemiology and Medical Care Unit, Northwick Park Hospital, Harrow, Middlesex, UK.
}

\begin{abstract}
Study objective: To determine the relationship between obesity and subsequent incidence of ischaemic heart disease (IHD).

Design: Prospective cohort survey.

Setting: Study of three occupational groups, with follow up examinations.

Subjects: 3500 people recruited between 1972 and 1978 (80\% response rate), and followed up between 1978 and 1984. This report is based on subgroup of 1511 white men aged 40-64 at entry.

Measurements and main results: Information was obtained on smoking and family history of IHD. Blood pressure, weight, height, skinfold thickness at four sites, fibrinogen, factor VII activity and cholesterol were measured during follow up. Body mass index (BMI) was used as an index of obesity. BMI was found to be more strongly correlated with IHD than any of the skinfold measurements, none of which was significantly associated with IHD when BMI was allowed for. Increase in BMI by $1 \mathrm{SD}(\sim 8 \mathrm{~kg})$ was associated with a $44 \%$ increase in the risk of IHD. Of the four skinfolds, subscapular was the most closely associated with risk, confirming the relevance of central obesity. The association between obesity and IHD remained when possible mechanisms for its effects were taken into account, and its strength may increase with time: for 1 SD increase in BMI, risk of events within 5 years was increased by $28 \%$, while risk of events after longer than 5 years was increased by $65 \%$.
\end{abstract}

Conclusions: Preventive strategies for IHD should include avoidance of obesity.

Many studies show an association between obesity and the risk of ischaemic heart disease (IHD), ${ }^{1-5}$ although some have not found a relationship. ${ }^{6-8}$ Most studies which have found an association have concluded that the adverse effect of obesity is mediated through mechanisms such as blood pressure or cholesterol. Another pathway may be through haemostatic variables.

There has recently been considerable interest in the suggestion that centrally located subcutaneous fat is particularly implicated in the causation of IHD. Waist/hip ratio has been shown to be associated with IHD in prospective studies, when body mass index was taken into account. ${ }^{910} \mathrm{~A}$ recent study has suggested that skinfold thickness, and in particular subscapular skinfold, is more closely associated with risk of subsequent heart disease than body mass index. ${ }^{11}$

We have compared the relationships of four separate skinfold thicknesses and body mass index with the risk of IHD. We have also assessed the extent to which the association between obesity and IHD appears to act through various mechanisms.

\section{Methods}

The main aim of the Northwick Park Heart Study is to investigate the thrombotic component of ischaemic heart disease by including measures of haemostatic function along with other indices of risk. The design, conduct and principal results have been reported elsewhere. ${ }^{1213}$ In brief, 3500 people were recruited between 1972 and 1978 from three occupational groups in north west London. The response rate was about $80 \%$. Follow up took place between 1978 and 1984. This report is based on the 1511 white men aged 40-64 at entry.

Participants were interviewed by trained nurses in a standard fashion. Information on smoking habit was obtained and blood pressure was measured using a standard sphygmomanometer with a $12 \times 23 \mathrm{~cm}$ bladder. A blood sample was taken, if possible without venecompression. Fibrinogen, factor VII activity and cholesterol were assayed using previously described techniques. ${ }^{12}$ Weight and height were measured on a Steven's beam balance with height attachment, the 
subject wearing light clothing. Body mass index (weight divided by height squared, in $\mathrm{kg} / \mathrm{m}^{2}$ ) was used as an index of obesity.

Participants were interviewed by a doctor in a standard way to determine whether there was any history of IHD. Skinfold thickness was measured at four sites-forearm, triceps, subscapular and suprailiac-using Holtain skinfold calipers as previously described. ${ }^{14}$ Three doctors took the majority of the measurements.

Full details of follow up procedures for mortality and IHD events have already been described. ${ }^{13}$ The term "all ischaemic heart disease" refers to the sum of fatal and non-fatal events in persons without a history of myocardial infarction at entry, ie, it excludes 52 men who had had an MI at recruitment.

Survival analysis using Cox's proportional hazards model ${ }^{15}$ were carried out with the skinfold thicknesses and body mass index as covariates, along with age and smoking status. These were entered into the regression first separately and then together. In further analyses, cholesterol, systolic blood pressure, fibrinogen and factor VII activity were also included as covariates. The proportionality assumption was checked by including a quadratic term as a covariate and a time dependent term. There was no significant departure from this assumption. The distributions of skinfold thickness and body mass index are skewed. However, since the use of log transformed data in the analyses made very little difference to the results, the results using untransformed data are presented.

The skinfold thickness results were adjusted for age and observer effects prior to survival analysis by using coefficients derived from multiple regression analysis.

The regression coefficients from the survival analysis have been standardised so that the standardised regression effect is equivalent to the change in relative risk associated with a 1 SD change in the variable under consideration. ${ }^{13}$

\section{Results}

The mean levels and standard deviations of the unadjusted skinfold thicknesses and body mass index (BMI) at entry to the study by categories of IHD event are shown in table 1.

A comparison of the relative strength of association between the skinfold thicknesses and risk of IHD, and between BMI and risk of IHD is made in table 2. The relative risk of IHD by low, middle and high thirds of the distributions of these measures of obesity is shown. The gradient of risk was steepest for BMI, and then for subscapular skinfold, both for fatal IHD and all IHD.

The standardised regression effects (table 3 ) also show that BMI was most strongly associated with IHD, followed by subscapular skinfold thickness, after allowing for effects of age and smoking. For a $1 \mathrm{SD}$ increase in BMI (on average $8 \mathrm{~kg}$ weight), the risk of an IHD event was $44 \%$ greater, while for a 1 SD increase in subscapular skinfold it was $25 \%$ greater.

There was a suggestion that the relationship between BMI and all IHD became stronger with time $(p=0.07$ for the interaction term). The standardised regression effect for all IHD events within 5 years was $1 \cdot 28$, while for events beyond 5 years it was $1 \cdot 65$. For all IHD events occurring within 5 years of follow up, mean BMI was $26 \cdot 2$, while for events occurring later it was $27 \cdot 0$. Similar results hold for fatal IHD alone.

There was no significant variation with age in the association between BMI and IHD (fatal or nonfatal). The mean BMI in men aged 40-59 having IHD events was 26.8 ( 25.4 in survivors), while for men aged $60-64$ it was $26 \cdot 1$ (25.5 in survivors). Similar results held for fatal IHD alone.

Only BMI was significantly associated with the risk of death from any cause. Mean levels in those dying of cancer $(n=48)$ or from other causes $(n=27)$ were 25.4 and 24.6 respectively, compared with 26.9 for fatal IHD.

Multiple regression analyses were performed including all the skinfold measures together. For all $I H D$, only the subscapular measurement approached significance $(p=0.07)$. When BMI was also included none of the skinfolds were significantly associated

Table 1 Values for skinfold thickness and body mass index at entry, by categories of IHD event. Results are means (SD)

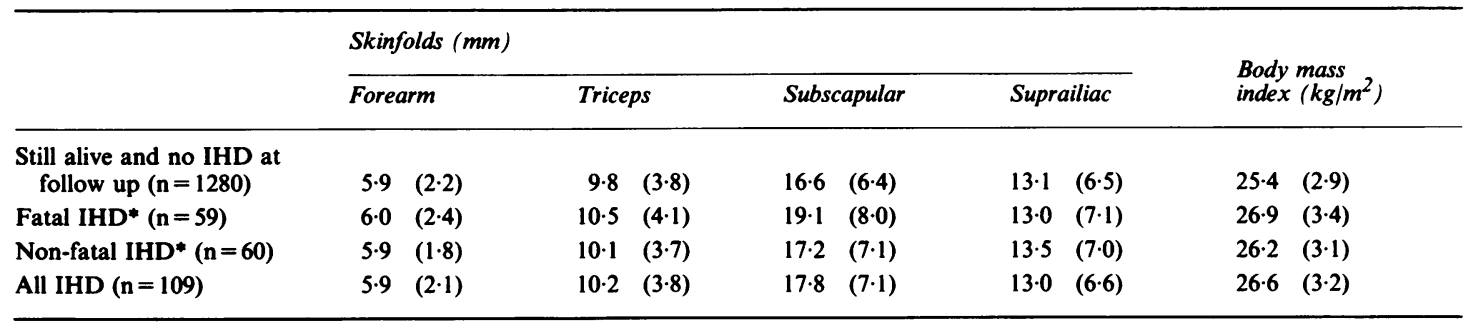

\footnotetext{
* Ten men had an episode of non-fatal IHD followed by a fatal episode.
} 
Table 2 Relative risks with (95\% confidence intervals) of fatal IHD and all IHD by tertiles of skinfold thickness and body mass index

\begin{tabular}{|c|c|c|c|c|c|}
\hline \multirow[b]{2}{*}{ Tertile } & \multicolumn{4}{|l|}{ Skinfolds } & \multirow{2}{*}{$\begin{array}{l}\text { Body mass } \\
\text { index }\end{array}$} \\
\hline & Forearm & Triceps & Subscapular & Suprailiac & \\
\hline \multicolumn{6}{|c|}{ Fatal IHD $(n=59)$} \\
\hline Low & 1 & 1 & 1 & 1 & 1 \\
\hline Middle & $\begin{array}{c}1.29 \\
(0.71-2 \cdot 34)\end{array}$ & $\begin{array}{c}1.36 \\
(0.71-2 \cdot 63)\end{array}$ & $\begin{array}{c}1 \cdot 90 \\
(0 \cdot 97-3 \cdot 71)\end{array}$ & $\begin{array}{c}1 \cdot 29 \\
(0 \cdot 72-2 \cdot 30)\end{array}$ & $\begin{array}{c}2.03 \\
0.96-4 \cdot 29)\end{array}$ \\
\hline High & $\begin{array}{c}1.08 \\
(0.57-2.06)\end{array}$ & $\begin{array}{c}1.72 \\
(0.91-3 \cdot 24)\end{array}$ & $\begin{array}{c}1.99 \\
(1.02-3.88)\end{array}$ & $\begin{array}{c}0.89 \\
(0.46-1 \cdot 72)\end{array}$ & $\begin{array}{c}3.02 \\
(1.49-6 \cdot 13)\end{array}$ \\
\hline \multicolumn{6}{|c|}{ All IHD $(n=109)$} \\
\hline Low & 1 & 1 & 1 & 1 & 1 \\
\hline Middle & $\begin{array}{c}1.41 \\
(0.91-2 \cdot 20)\end{array}$ & $\begin{array}{c}1.23 \\
(0.77-1.95)\end{array}$ & $\begin{array}{c}1 \cdot 54 \\
(0 \cdot 97-2 \cdot 46)\end{array}$ & $\begin{array}{c}1 \cdot 10 \\
(0 \cdot 72-1 \cdot 69)\end{array}$ & $\begin{array}{c}2 \cdot 11 \\
(1 \cdot 24-3 \cdot 60)\end{array}$ \\
\hline High & $\begin{array}{c}1.33 \\
(0.84-2 \cdot 11)\end{array}$ & $\begin{array}{c}1.42 \\
(0.90-2 \cdot 22)\end{array}$ & $\begin{array}{c}1.65 \\
(1.04-2.63)\end{array}$ & $\begin{array}{c}1.00 \\
(0.64-1.57)\end{array}$ & $\begin{array}{c}2.84 \\
(1.70-4.74)\end{array}$ \\
\hline
\end{tabular}

Tertile cutting points $(\mathrm{mm})$ : Forearm 4.7, 6.5; $\quad$ Triceps 7.9, 10.7; $\quad$ Subscapular 13.3, 18.5; $\quad$ Suprailiac 9.5, 15.1; $\quad$ Body mass index $\left(\mathrm{kg} / \mathrm{m}^{2}\right)$ 24.3, $26 \cdot 6$

Table 3 Standardised regression effects (SRE), with (95\% confidence intervals) and $p$ values for fatal IHD, all IHD and total mortality of separate skinfold thicknesses and body mass index

\begin{tabular}{|c|c|c|c|c|c|}
\hline & \multicolumn{4}{|c|}{ Skinfolds ( $\mathrm{mm}$ ) } & \multirow{2}{*}{$\begin{array}{l}\text { Body mass } \\
\text { index }\left(\mathrm{kg} / \mathrm{m}^{2}\right)\end{array}$} \\
\hline & Forearm & Triceps & Subscapular & Suprailiac & \\
\hline \multicolumn{6}{|l|}{ Fatal IHD } \\
\hline SRE & $\begin{array}{c}1 \cdot 18 \\
(0.91-1 \cdot 52)\end{array}$ & $\begin{array}{c}1.31 \\
(1.04-1.64)\end{array}$ & $\begin{array}{c}1.44 \\
(1 \cdot 17-1.79)\end{array}$ & $\begin{array}{c}1 \cdot 16 \\
(0.90-1 \cdot 49)\end{array}$ & $\begin{array}{c}1.62 \\
(1.29-2.05)\end{array}$ \\
\hline$p$ value & 0.2 & 0.03 & 0.002 & 0.3 & 0.0001 \\
\hline \multicolumn{6}{|l|}{ All IHD } \\
\hline SRE & $\begin{array}{c}1 \cdot 14 \\
(0.95-1 \cdot 37)\end{array}$ & $\begin{array}{c}1.20 \\
(1.01-1 \cdot 43)\end{array}$ & $\begin{array}{c}1.25 \\
(1.05-1.47)\end{array}$ & $\begin{array}{c}1 \cdot 14 \\
(0.95-1 \cdot 37)\end{array}$ & $\begin{array}{c}1.44 \\
(1 \cdot 21-1.71)\end{array}$ \\
\hline p value & $0 \cdot 2$ & 0.05 & 0.01 & 0.2 & 0.0001 \\
\hline \multicolumn{6}{|l|}{ All deaths } \\
\hline & $\begin{array}{c}0.96 \\
(0.80-1 \cdot 17)\end{array}$ & $\begin{array}{c}1.13 \\
(0.95-1.34)\end{array}$ & $\begin{array}{c}1 \cdot 14 \\
(0.97-1 \cdot 34)\end{array}$ & $\begin{array}{c}0.96 \\
(0.79-1 \cdot 16)\end{array}$ & $\begin{array}{c}1.21 \\
(1.03-1 \cdot 43)\end{array}$ \\
\hline p value & 0.7 & 0.2 & 0.1 & 0.6 & 0.02 \\
\hline
\end{tabular}

* For definition see text.

with IHD. Conversely, body mass index remained significantly associated with IHD after all the skinfolds were added $(\mathrm{p}=0.0006)$.

For fatal IHD, only subscapular skinfold thickness was significantly associated $(p=0.002)$. When BMI was added there was a weak negative association with suprailiac skinfold $(p=0.04)$, but there was no association with the subscapular measurement. BMI remained significantly associated after all the skinfolds were added $(p=0.003)$.

To assess the independent effect of obesity on the risk of IHD the survival analyses were repeated, including factor VII, cholesterol, systolic blood pressure and fibrinogen as covariates. For all IHD, BMI remained significantly associated $(p=0.002)$ with a slightly reduced SRE 1.36 (cf 1.44). The SRE was reduced by a similar small amount (between 1 and $3 \%$ ) as each covariate entered the regression. Systolic blood pressure was associated with the largest reduction. For subscapular skinfold the association was no longer significant $(p=0 \cdot 1)$ and the SRE was reduced to $1 \cdot 16$ (cf $1 \cdot 25)$.

In the case of fatal IHD, the association of body mass index with IHD risk was still significant $(p=0.001)$ with an SRE of 1.57 (cf 1.62). In the regression, cholesterol was associated with the largest reduction in the SRE. Subscapular skinfold $(p=0.02)$ was also independently associated, with an SRE 1.34 (cf 1.44).

For events of IHD within 5 years, after inclusion of 
these risk factors the SRE for BMI was reduced to $1 \cdot 19$ $(p=0 \cdot 2)$. For events beyond 5 years the SRE was reduced to $1.60(p=0.001)$.

\section{Discussion}

An association between obesity and the risk of IHD was originally found in life insurance data. ${ }^{14}$ The results of epidemiological studies carried out more recently have been equivocal. In some, no significant association was found, ${ }^{616}$ in others the association was no longer evident after taking risk factors such as blood pressure or cholesterol into account. ${ }^{717}$ Some have shown a link independent of the risk factors measured. ${ }^{235}$ Our results show a clear link between obesity and IHD which is independent of its association with established risk factors.

The apparently conflicting findings of different studies may arise from differences in the range and degree of obesity, the ages of the cohorts, or the length of follow up. For example, many of the populations in the Seven Countries Study were, on average, leaner than the Northwick Park Heart Study population, which is comparable to the rest of the UK in terms of obesity. ${ }^{18}$ As others have shown, ${ }^{2-4}$ the Northwick Park Study found the contribution of obesity to IHD risk is strongest in younger men and over greater lengths of follow up although these associations were not statistically significant. Results of the Whitehall Study showed that initially there was no relationship between obesity and IHD in men aged $40-49$ but that after 10 years of follow up there was a significant association. ${ }^{1617}$

Obesity and cholesterol, factor VII, fibrinogen and blood pressure are associated in cross sectional data $^{19}$ and changes in obesity result in changes in these variables, with the possible exception of fibrinogen. ${ }^{20-22}$ Our results suggest that although obesity may predispose to IHD partly through these mechanisms these do not appear to be solely responsible for its association with IHD.

We have shown that body mass index is more closely associated with subsequent IHD (both fatal and non-fatal) than skinfold thickness. Skinfold thickness is subject to greater measurement error than weight and height, but we have attempted to adjust for systematic variation between observers. Subscapular skinfold is the most closely related of the four skinfolds to IHD. This may be further evidence for the role of centrally located subcutaneous fat in the causation of IHD.

Our results, from a contemporary study of a UK population, suggest that the reduction of obesity should be given more prominence in cardiovascular disease prevention.
We thank staff at $\mathbf{H} \mathbf{J}$ Heinz Co Ltd, British Telecom and the offices of the London boroughs of Harrow and Brent for their help and participation; laboratory, nursing and clerical staff in the Medical Research Council's Epidemiology and Medical Care Unit for their help. We acknowledge the contribution of the late Sir Graham Bull, Professor R L Himsworth, Dr W E Miall, Dr C J Edmonds and Dr Gillian Greenberg in assessing cases.

Address for correspondence and reprints: Professor A P Haines, Department of Primary Health Care, University College and Middlesex School of Medicine, Highgate Wing, Whittington Hospital, London N19 5HT.

\section{References}

${ }^{1}$ Build and Blood Pressure Study 1959. Chicago: Society of Actuaries, 1959.

${ }^{2}$ Hubert HB, Feinleib M, McNamara PM, et al. Obesity as an independent risk factor for cardiovascular disease: $\mathbf{A}$ 26-year follow-up of participants in the Framingham Heart Study. Circulation 1983; 67: 968-77.

${ }^{3}$ Rabkin SW, Mathewson FAL, Hsu PH, et al. Relation of body weight to development of ischaemic heart disease in a cohort of young North American men after a 26 year observation period: The Manitoba Study. Am J Cardiol 1977; 39: 452-8.

${ }^{4}$ Blair BF, Haines LW. Mortality experience according to build at higher durations. Trans Actuarial Soc America, 1966; 18: 35-41.

${ }^{5}$ Robertson TL, Kato H, Gordon T, et al. Epidemiological studies of coronary disease and stroke in Japanese men living in Japan, Hawaii and California. Am J Cardiol 1977; 39: 244-9.

${ }^{6}$ Westlund $K$, Nicolaisen $R$. Ten year mortality and morbidity related to serum cholesterol. Scand J Clin Lab Invest 1972; 30 (suppl 127): 1-24.

${ }^{7}$ Rosenman RH, Brand RJ, Scholtz RI, et al. Multivariate prediction of coronary heart disease during 8.5 year follow up in the Western Collaborative Group Study. Am J Cardiol 1976; 37: 903-10.

${ }^{8}$ Keys A. Seven countries. A Multivariate analysis of death and coronary heart disease. Cambridge, MA: Harvard University Press, 1980.

${ }^{9}$ Larsson B, Svardsudd K, Welin L, Wilhelmsen L, Bjorntorp P, Tibblin F. Abdominal adipose tissue distribution, obesity and risk of cardiovascular disease and death: 13 year follow up of participants in the study of men born in 1913. Br Med J 1984; 288: 1401-4.

${ }^{10}$ Lapidus L, Bengtsson C, Larsson B, Pennert K, Rybo E, Sjostrom L. Distribution of adipose tissue and risk of cardiovascular disease and death: a 12 year follow up of participants in the population study of women in Gothenburg, Sweden. Br Med J 1984; 289: 1257-61.

11 Donahue RP, Abbott RD, Bloom E, Reed DM, Yano K. Central obesity and coronary heart disease in men. Lancet 1987; i: 821-4.

12 Meade TW, North WRS, Chakrabarti R, Haines AP, Stirling Y. Population-based distributions of haemostatic variables. Br Med Bull 1977; 33: 283-8. 
${ }^{13}$ Meade TW, Brozovic M, Chakrabarti RR, et al. Haemostatic function and ischaemic heart disease: principal results of the Northwick Park Heart Study. Lancet 1987; i: 533-7.

${ }^{14}$ Haines AP, Imeson JD, Meade TW. Skinfold thickness and cardiovascular risk factors. Am J Epidemiol 1987; 126: 86-94.

${ }^{15}$ Hopkins A. Regression with incomplete survival data. In: Dixon WJ, Brown MB, eds. BMDP statistical software. Los Angeles: University of California Press, 1983: 576-94.

16 Reid DD, Hamilton PJS, McCartney P, Rose G, Jarrett RJ, Keen H. Smoking and other risk factors for coronary heart disease in British civil servants. Lancet 1976; ii: 979-84.

17 Jarrett RJ, Shipley MJ, Rose G. Weight and mortality in the Whitehall Study. Br Med J 1982; 285: 535-7.

18 Cox BD. Body measurements (heights, weights, girths, etc). In: The Health and Lifestyle Survey. London: Health Promotion Research Trust, 1987: 35-41.
${ }^{19}$ Meade TW. Epidemiology of atheroma, thrombosis and ischaemic heart disease. In: Bloom AL, Thomas DP, eds. Haemostasis and thrombosis. Edinburgh: Churchill Livingstone, 1987: 677-720.

${ }^{20}$ Haines AP. The relation between obesity and haemostatic variables, standard cardiovascular risk factors and mortality. London: University of London, 1985. MD Thesis.

${ }^{21}$ Meade TW, Imeson J, Stirling Y. Effects of changes in smoking and other characteristics on clotting factors and the risk of ischaemic heart disease. Lancet 1987; ii: 986-8.

${ }^{22}$ Ashley FW, Kannel WB. Relation of weight change to changes in atherogenic traits: The Framingham Study. $J$ Chron Dis 1974; 27: 103-14.

Accepted for publication February 1989 